\title{
Numerical Simulation of Groundwater Flow of Emergency Water Source in Nanchang City
}

\author{
Qingshan $\mathrm{Ma}^{1 *}$, Junyuan $\mathrm{Jia}^{1}$, Fujin Tian ${ }^{1}$, Ting Lei ${ }^{1}$, and Changjian Chen ${ }^{2}$ \\ ${ }^{1}$ Nanjing Center, China geological survey, Jiangsu, 210016, China \\ ${ }^{2}$ School of Water Resources \& Environmental Engineering, East China University of Technology, Jiangxi, 330013, China
}

\begin{abstract}
The source of water supply in Nanchang City is relatively single, and the safety of urban water supply is difficult to guarantee. According to the hydrogeological conditions of the study area, a threedimensional visualization numerical model of groundwater system was established. After the model identification and verification, combined with the target of emergency water supply in Nanchang city, the emergency exploitation of groundwater in Youkou emergency water source was simulated by using the model under different emergency exploitation schemes, respectively. The prediction results show that compared with scheme I and scheme II, scheme III is most suitable for the requirements of well layout, which has the advantages with the minimum drawdown of groundwater level, and the maximum exploitation. For scheme III, under the conditions that the dewatered aquifers are no more than $1 / 2$ and $2 / 3$ of the original aquifer, the emergency exploitation of $36.55 \times 10^{4} \mathrm{~m}^{3} / \mathrm{d}$ and $49.45 \times 10^{4} \mathrm{~m}^{3} / \mathrm{d}$ can be provided, which could meet the emergency water demands of $54.9 \%$ and $74.3 \%$ of the local residents, respectively.
\end{abstract}

\section{Introduction}

At present, there are many water supply plants in Nanchang City, such as Xiazheng Street Water Plant, Chaoyang Water Plant, Qingyun Water Plant, Niuhang Water Plant, and Shuanggang Water Plant etc. However, all of them take Ganjiang River water as their water source [1]. This single water resource pattern does not match the increasing water consumption, which has become a major potential threat to the safe operation of cities [2-5]. After the flood season in 2003, a rare drought occurred in Jiangxi Province. The water level of Ganjiang River reached the lowest point, and some river sections were cut off. Many water intakes in Nanchang were unable to get water. The water supply in the whole city was in an unprecedented shortage and emergency. In 2019, Jiangxi encountered another rare drought in history. The riverbed of the Ganjiang River dried up, exposed and cracked, the lake centre of Poyang Lake became grassland, and the lake bed dried up. Compared with surface water, groundwater is of good quality, with even spatial and temporal distribution, and relatively stable dynamics, which is suitable as an emergency water source [6]. In response to the sudden increase of natural and man-made disasters in recent decades, the UNESCO International Hydrological Project has undertaken the GWES (Groundwater for Emergency Situations) project, and provided methodological guidance for groundwater as an emergency water source [7]. Therefore, research on the emergency ability of groundwater emergency water sources is of great practical significance to improve the city's ability to respond to emergencies [8], and ensure the safety of urban water supply.

\section{Study area}

The study area is located in the plain area of the lower reaches of Ganjiang and Fuhe River. The surface is covered by loose river alluviums, and the underlying is Tertiary sandstone and glutenite. The Quaternary is widely distributed in the area, with a thickness of $20 \sim 30 \mathrm{~m}$. The groundwater is mainly loose pore water. Most aquifers are of binary structure, which is relatively simple. The lower sandy soil is the main aquifer, with a thickness of $10 \sim 20 \mathrm{~m}$, and has an abundance of water. The comprehensive permeability coefficient of the aquifer is about $80 \sim 120 \mathrm{~m} / \mathrm{d}$, the depth of groundwater level is about $9 \sim 15 \mathrm{~m}$, and the water level changes by $3 \sim 5 \mathrm{~m}$. The dynamics of pore water level is controlled by atmospheric precipitation and the water level rises during the wet season and decreases during the dry season. The change of groundwater level generally lags behind precipitation by $10 \sim 30$ days.

The vertical recharge of study area is dominated by atmospheric precipitation. Due to the double-layer structure of the pore aquifer, so the vertical recharge condition is relatively poor. Two main precipitation recharge areas are located in the east and west of the study area, which includes Wugangwei, Luojiaji, Liantang and other places. The Fuhe River and its tributaries in the east of the study area have a weak hydraulic connection with groundwater. During the

\footnotetext{
* Corresponding author: ssqm2007@163.com
} 
water holding period, the recharge of paddy field to groundwater is also very weak.

The red bed is widely concealed below the Quaternary loose soil layer, and the elevation is about$30 \sim-60 \mathrm{~m}$. The red bed aquifers have good connectivity and form a continuous and uniform confined water level. Due to long-term weathering damage, the fissures are relatively developed and have certain water permeability, which results in a cross-flow connection between the "red bed" aquifer and the overlying loose pore aquifer. The hydrogeological profile of the study area is shown in Figure 1.

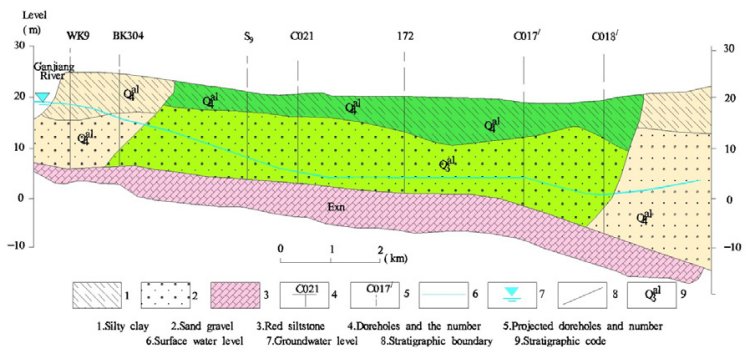

Fig.1. Hydrogeological sketch map of the area from Bayi Bridge to Nanchang Iron and Steel Plant

\section{Model implement}

\subsection{Hydrogeological conceptual model}

The northwest side of the calculation area is the south branch of Ganjiang river, and the east and west side are the boundaries of Nanchang planning area, includes Donghu district, Xihu district, Qingshanhu district, Qingyunpu district and some areas of Nanchang County, with an area of about $651 \mathrm{~km}^{2}$. The calculation area is shown in Figure 2.

In this study, the whole calculation area is divided into five layers according to lithology and water yield. From the top to bottom, they are the weak aquifer of cohesive soil, the unconfined aquifer of the upper section of sand gravel layer, the confined aquifer of the lower section of sand gravel layer, the confined aquifer of the upper section of red siltstone and the confined aquifer of the lower section of red siltstone. Each layer is generally heterogeneous and anisotropic, and there is a close hydraulic relationship between aquifers. Recharge was assigned to the top of Layer 1 to receive both natural recharge (calculated as precipitation less runoff and evapotranspiration) and estimated leakage of agricultural irrigation water. The base of Layer 5 was set as a noflow boundary. There is a close hydraulic connection among the boundary of each layer, and the flow boundary is generalized all around the model.

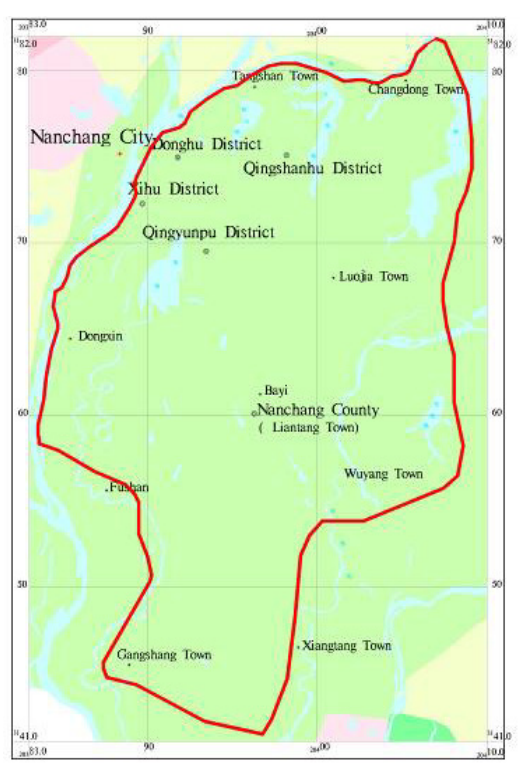

Fig.2. Schematic diagram of calculation area

\subsection{Mathematic model}

Based on the continuity principle and Darcy's law, and with coordinates aligned in the principal permeability directions of the anisotropic porous media, the 3-D unsteady flow equation for porous media can be expressed as [9-10]:

$$
\begin{aligned}
& \frac{\partial}{\partial x}\left(K_{x x} \frac{\partial h}{\partial x}\right)+\frac{\partial}{\partial y}\left(K_{y y} \frac{\partial h}{\partial y}\right)+\frac{\partial}{\partial z}\left(K_{z z} \frac{\partial h}{\partial z}\right) \\
& +W=S_{s} \frac{\partial h}{\partial t} \quad(x, y, z) \in \Omega
\end{aligned}
$$

where: $K_{x x}, K_{y y}$ and $K_{z z}$ are, respectively, the hydraulic conductivities in the principal directions of anisotropy, $h$ is the groundwater head, $W$ is a source/sink term, $S_{s}$ is the specific storage, $t$ is time, and $\Omega$ is the computational domain.

The initial condition and boundary conditions for the unsteady seepage calculation are defined as follows:

(1) Initial condition:

$$
\left.h(x, y, z, t)\right|_{t=0}=h_{0}(x, y, z) \quad(x, y, z \in \Omega)
$$

where $h_{0}(x, y, z)$ is the initial head at point $(x, y, z)$.

(2) Boundary conditions:

$$
\left\{\begin{array}{lc}
\left.h(x, y, z, t)\right|_{\Gamma_{1}}=h_{1}(x, y, z, t) & t>0, \quad(x, y, z) \in \Gamma_{1} \\
K_{x x} \frac{\partial h}{\partial x} \cos (n, x)+K_{y y} \frac{\partial h}{\partial y} \cos (n, y)+\left.K_{z z} \frac{\partial h}{\partial z} \cos (n, z)\right|_{\Gamma_{2}} \\
=q(x, y, z, t) & t>0, \quad(x, y, z) \in \Gamma_{2} \\
h(x, y, z, t)=z & t>0, \quad(x, y, z) \in \Gamma_{3} \\
\left.K \frac{\partial h}{\partial n}\right|_{\Gamma_{3}}=-\mu \frac{\partial h}{\partial t} \cos \theta &
\end{array}\right.
$$


where: $h_{1}(x, y, z, t)$ is the known head at Dirichlet boundaries $\Gamma_{1} ; q(x, y, z, t)$ is the normal unit flux at Neumann boundaries $\Gamma_{2}$. For no flow boundaries, $q$ equals zero. $\cos (n, x), \cos (n, y)$ and $\cos (n, z)$ are the directional cosines for the normal to the body surface, $z$ is the elevation of the free surface, $\mu$ is the saturation deficiency (for a free surface rise) or the specific yield (for a free surface decline), $\theta$ is the angle between the normal vector to the outer boundary and the perpendicular and $\Gamma_{3}$ is the free surface.

\subsection{Identification and Verification}

According to the geometry of calculation area, the structural characteristics of the groundwater system and the distribution of the pumping wells, the calculation area is divided into three dimensions. The computational domain is divided into 41,801 triangular elements and 21,053 nodes on the plane. Taking into account the influence of pumping wells, observation wells and layer thicknesses, it is divided into 5 layers and 6 calculation slices, totalling 209,005 units and 126,318 nodes. The mesh generation in plane is shown in Figure 3.

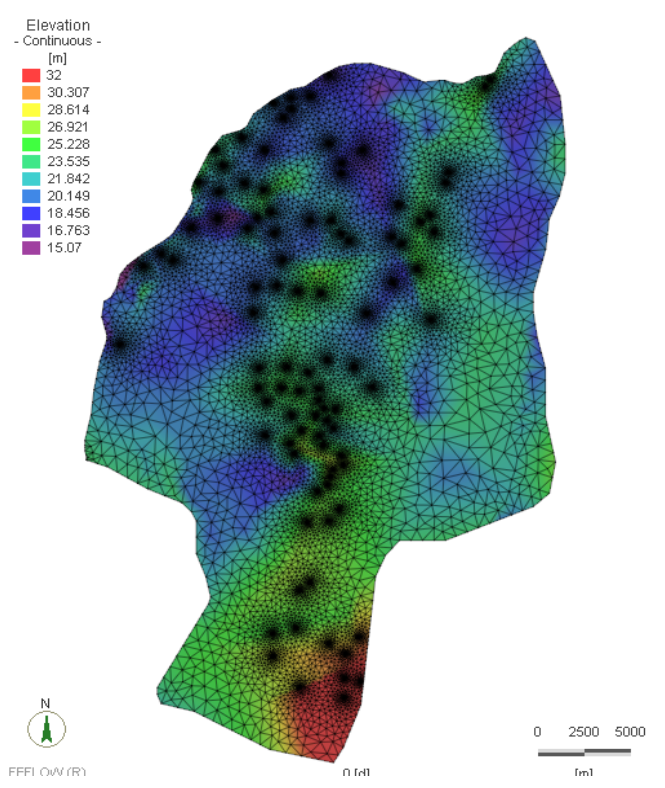

Fig.3. Mesh generation in Plane

Upon analysis of the existing data of groundwater level, the model calibration and verification period was determined from 1 January 2017 to 31 December 2018. Each month was taken as a stress period of exploitation and there were 24 stress periods in total.

The initial heads of all aquifers were obtained directly by Kriging interpolation from the observed data. Initial values of soil property (hydraulic conductivity, specific storage and specific yield) were obtained from a variety of sources including pumping tests, soil tests and the literature. All model properties were refined during the calibration process and, in its final form, the model included 70 soil property zones. The model was calibrated against historical records of groundwater level using a trial and error procedure. The distribution of observation wells is shown in Figure 4. The parameter zones of the unconfined aquifer of the upper section of sand gravel layer are shown in Figure 5 as an example. Head calibration results are shown in Figure 6.

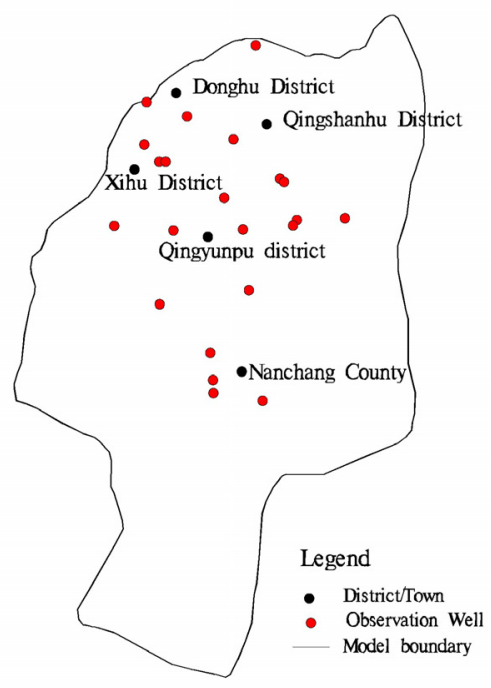

Fig.4. Distribution of observation wells within the calculation area

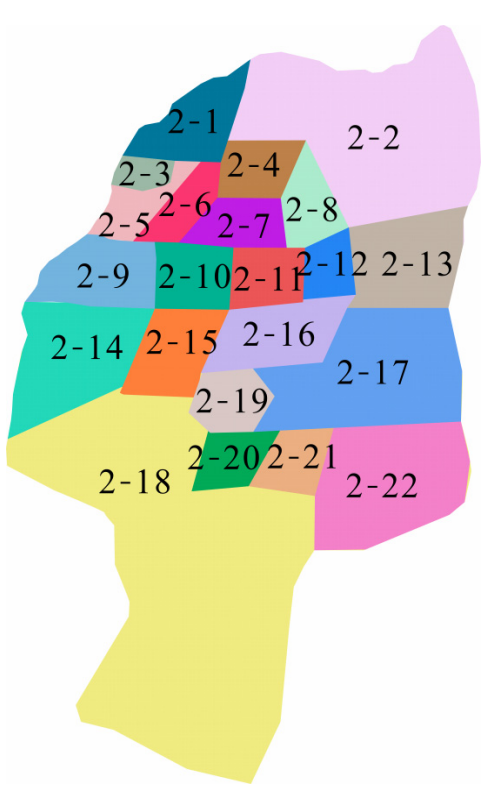

Fig.5. Hydrological parameters zones of unconfined aquifer

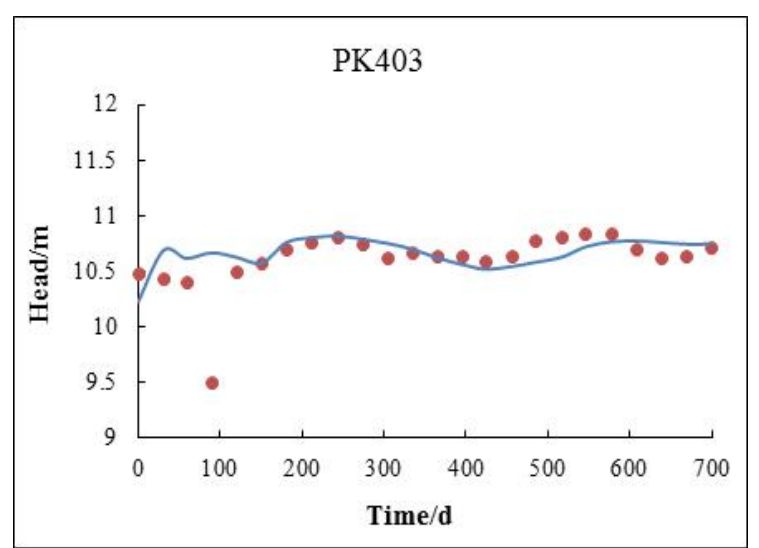




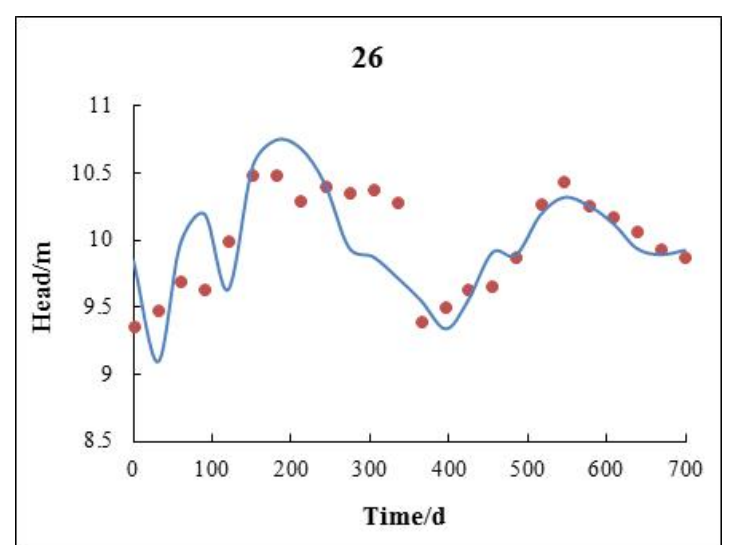

Fig.6. Comparison between observed (points) and simulated (solid lines) heads at observation wells

From the Fig.6, it can be seen that there is a good matching between calculated value and the observed value for observation well no. PK403 and 26, which meets the accuracy requirements, and the model can be used for simulation prediction.

\section{Emergency exploitation calculations}

\subsection{Water supply target}

According to the text of Nanchang City Master Plan (2001 2020), the water consumption of the central city is $182 \times 10^{4} \mathrm{~m}^{3} / \mathrm{d}$, including the water consumption of $126 \times 10^{4} \mathrm{~m}^{3} / \mathrm{d}$ in the South City and $56 \times 10^{4} \mathrm{~m}^{3} / \mathrm{d}$ in the North city by 2020 . The ratio of domestic water, industrial water and other water is 55:35:10. In the case of emergency water supply, the domestic water consumption shall be met first. According to the plan, the total domestic water supply scale of Nanchang urban area will be $100.1 \times 10^{4} \mathrm{~m}^{3} / \mathrm{d}$ by 2020 , including the emergency water supply of $69.3 \times 10^{4} \mathrm{~m}^{3} / \mathrm{d}$ and $30.8 \times 10^{4} \mathrm{~m}^{3} / \mathrm{d}$ for Changnan and Changbei, respectively.

\subsection{Emergency exploitation calculations}

\subsubsection{Scheme I: 79 pumping wells with a spacing of $300 m$}

Under the condition that the dewatered aquifer is no more than $1 / 2$ of the original aquifer, the exploitation of each well is $4200 \mathrm{~m}^{3} / \mathrm{d}$. After three months, the maximum, minimum and average drawdown of groundwater level is $12.57 \mathrm{~m}, 6.11 \mathrm{~m}, 9.99 \mathrm{~m}$, respectively. The percentage of dewatered aquifer thickness in the original aquifer thickness is $47.95 \%$ at the maximum, $24.00 \%$ at the minimum, and $37.98 \%$ on average, which meets the requirements of emergency water supply under the constraint condition. The emergency exploitation is $33.18 \times 10^{4} \mathrm{~m}^{3} / \mathrm{d}$. The seepage field of groundwater after three months is as shown in the Figure 7a.

Under the condition that the dewatered aquifer is no more than $2 / 3$ of the original aquifer, the exploitation of each well is $5800 \mathrm{~m}^{3} / \mathrm{d}$. After three months, the maximum, minimum and average drawdown of groundwater level is $18.15 \mathrm{~m}, 7.05 \mathrm{~m}, 13.81 \mathrm{~m}$, respectively. The percentage of dewatered aquifer thickness in the original aquifer thickness is $65.88 \%$ at the maximum, $27.57 \%$ at the minimum, and $52.37 \%$ on average, which meets the requirements of emergency water supply under the constraint condition. The emergency exploitation is $45.82 \times 10^{4} \mathrm{~m}^{3} / \mathrm{d}$. The seepage field of groundwater after three months is as shown in the Figure $7 \mathrm{~b}$. The layout of exploitation wells for scheme I is shown in the Figure 8 .

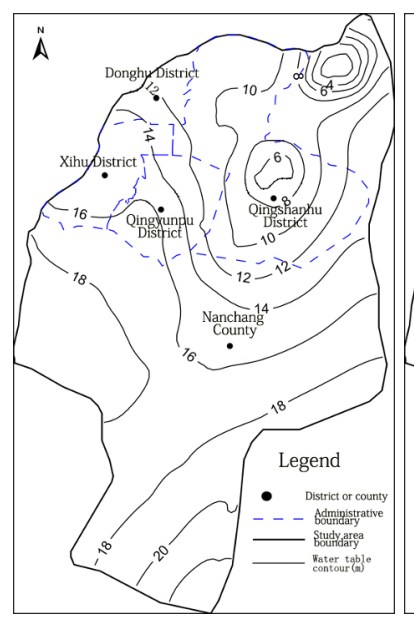

(a)

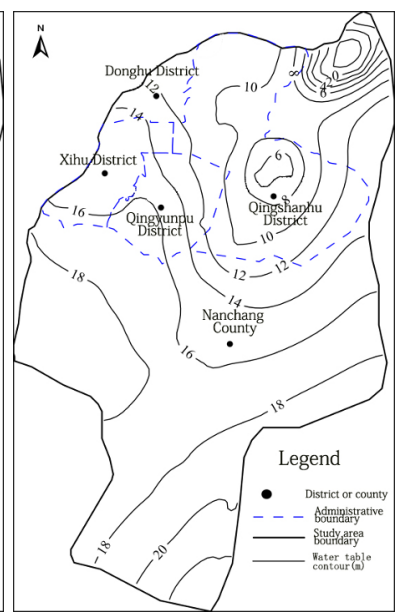

(b)
Fig. 7. Seepage field of groundwater after three months (scheme I)

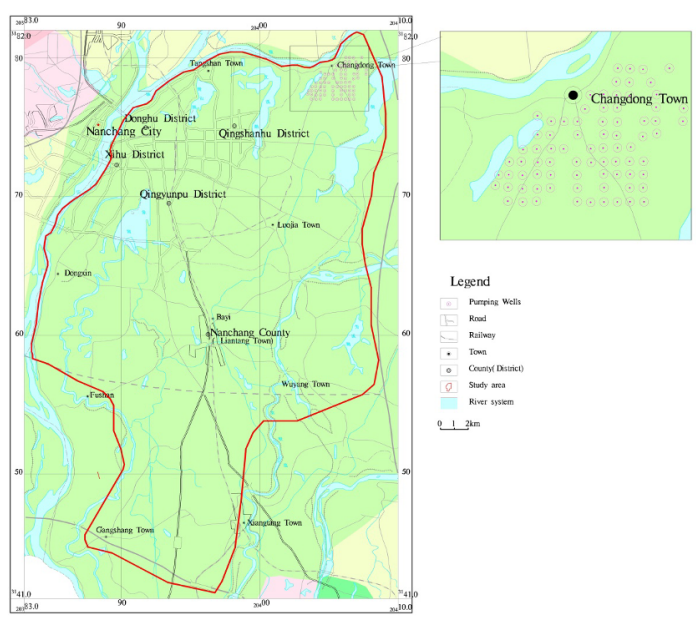

Fig. 8. The layout of exploitation wells for scheme I

\subsubsection{Scheme II: 52 pumping wells with a spacing of $450 \mathrm{~m}$}

Under the condition that the dewatered aquifer is no more than $1 / 2$ of the original aquifer, the exploitation of each well is $6800 \mathrm{~m}^{3} / \mathrm{d}$. After three months, the maximum, minimum and average drawdown of groundwater level is $13.47 \mathrm{~m}, 4.88 \mathrm{~m}, 10.91 \mathrm{~m}$, respectively. The percentage of drained aquifer thickness in the original aquifer thickness is $50.34 \%$ at the maximum, $24.00 \%$ at the minimum, and $22.06 \%$ on average, which meets the requirements of emergency water supply under the constraint condition. The emergency exploitation is 
$35.36 \times 10^{4} \mathrm{~m}^{3} / \mathrm{d}$. The seepage field of groundwater after three months is as shown in the Figure 9a.

Under the condition that the dewatered aquifer is no more than $2 / 3$ of the original aquifer, the exploitation of each well is $8800 \mathrm{~m}^{3} / \mathrm{d}$. After three months, the maximum, minimum and average drawdown of groundwater level is $17.36 \mathrm{~m}, 6.83 \mathrm{~m}, 14.10 \mathrm{~m}$, respectively. The percentage of drained aquifer thickness in the original aquifer thickness is $64.82 \%$ at the maximum, $30.88 \%$ at the minimum, and $53.31 \%$ on average, which meets the requirements of emergency water supply under the constraint condition. The emergency exploitation is $45.76 \times 10^{4} \mathrm{~m}^{3} / \mathrm{d}$. The seepage field of groundwater after three months is as shown in the Figure 9b. The layout of exploitation wells for scheme II is shown in the Figure 10.

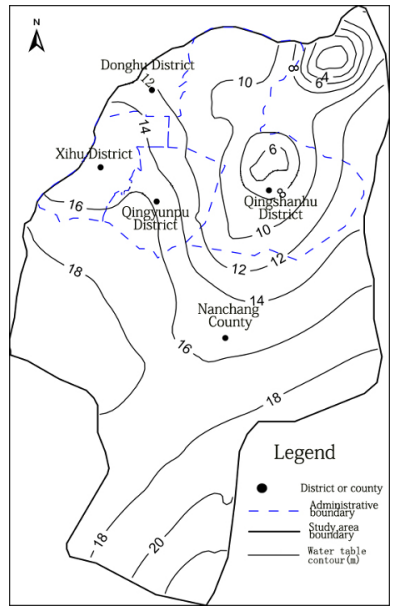

(a)

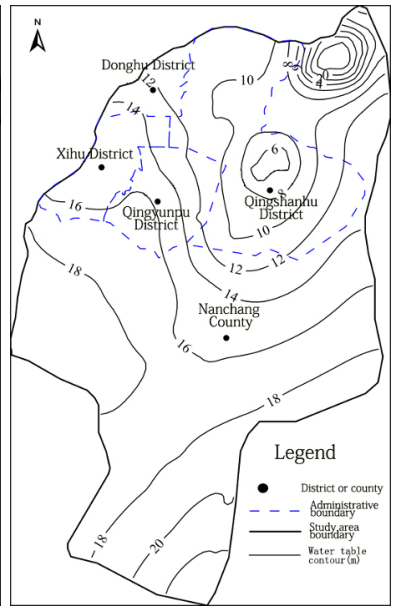

(b)
Fig. 9. Seepage field of groundwater after three months (scheme II)

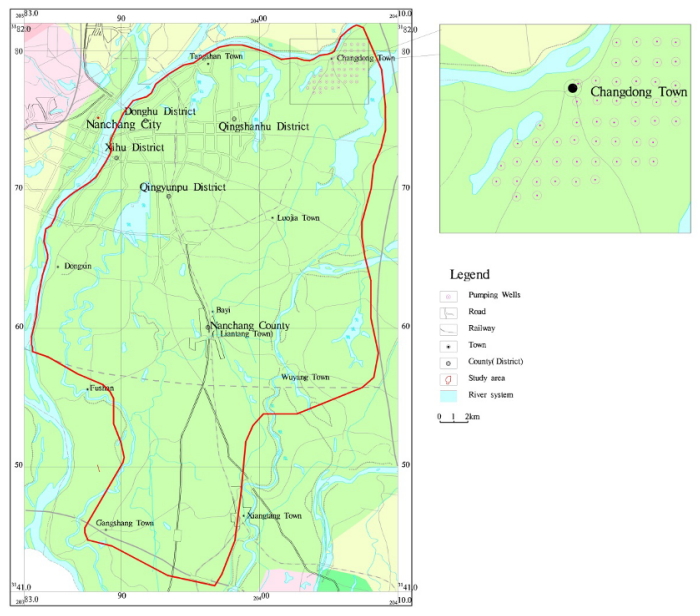

Fig. 10. The layout of exploitation wells for scheme II

\subsubsection{Scheme III: 43 pumping wells with a spacing of $500 \mathrm{~m}$}

Under the condition that the dewatered aquifer is no more than $1 / 2$ of the original aquifer, the exploitation of each well is $8500 \mathrm{~m}^{3} / \mathrm{d}$. After three months, the maximum, minimum and average drawdown of groundwater level is
$12.16 \mathrm{~m}, 5.76 \mathrm{~m}, 9.76 \mathrm{~m}$, respectively. The percentage of drained aquifer thickness in the original aquifer thickness is $47.17 \%$ at the maximum, $25.31 \%$ at the minimum, and $37.72 \%$ on average, which meets the requirements of emergency water supply under the constraint condition. The emergency exploitation is $36.55 \times 10^{4} \mathrm{~m}^{3} / \mathrm{d}$. The seepage field of groundwater after three months is as shown in the Figure 11a.

Under the condition that the dewatered aquifer is no more than $2 / 3$ of the original aquifer, the exploitation of each well is $11500 \mathrm{~m}^{3} / \mathrm{d}$. After three months, the maximum, minimum and average drawdown of groundwater level is $16.47 \mathrm{~m}, 8.1 \mathrm{~m}, 13.24 \mathrm{~m}$, respectively. The percentage of drained aquifer thickness in the original aquifer thickness is $63.94 \%$ at the maximum, $35.59 \%$ at the minimum, and $51.19 \%$ on average, which meets the requirements of emergency water supply under the constraint condition. The emergency exploitation is $49.45 \times 10^{4} \mathrm{~m}^{3} / \mathrm{d}$. The seepage field of groundwater after three months is as shown in the Figure 11b.The layout of exploitation wells for scheme III is shown in the Figure 12.

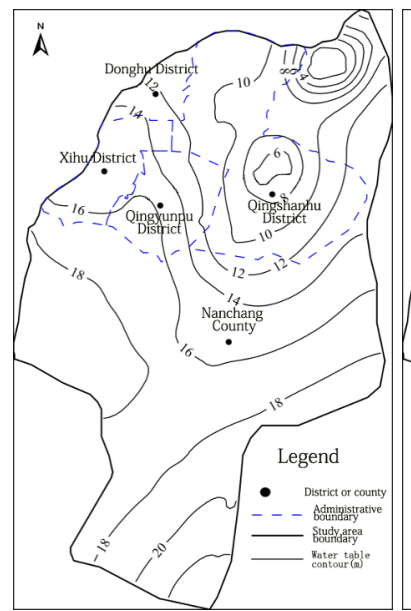

(a)

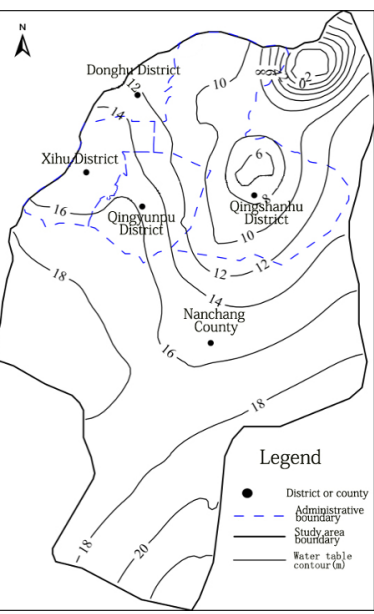

(b)
Fig. 11. Seepage field of groundwater after three months (scheme III)

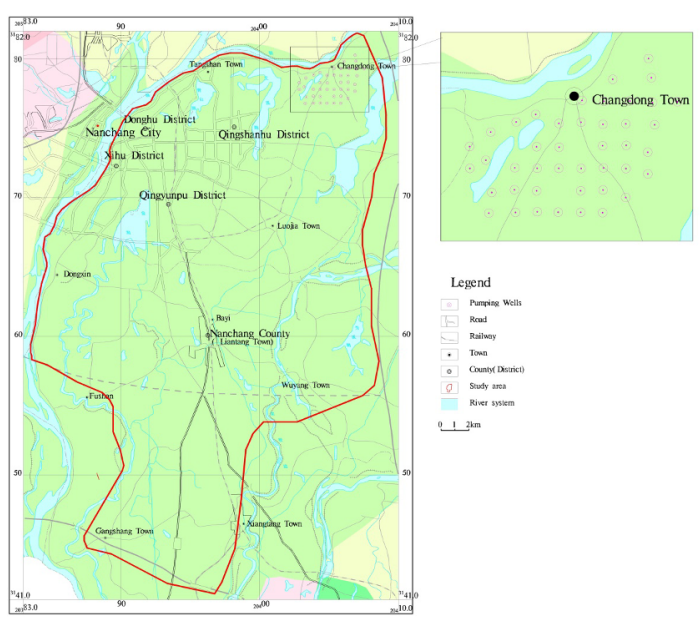

Fig. 12. The layout of exploitation wells for scheme III

\subsubsection{Results analysis}


Under the condition that the dewatered aquifer is no more than $1 / 2$ of the original aquifer, the emergency water supply of the three schemes is $33.18 \times 10^{4} \mathrm{~m}^{3} / \mathrm{d}$, $35.36 \times 10^{4} \mathrm{~m}^{3} / \mathrm{d}$ and $36.55 \times 10^{4} \mathrm{~m}^{3} / \mathrm{d}$, respectively. Under the condition that the dewatered aquifer is no more than $2 / 3$ of the original aquifer, the emergency water supply of the three schemes is $45.82 \times 10^{4} \mathrm{~m}^{3} / \mathrm{d} 、 45.76 \times 10^{4} \mathrm{~m}^{3} / \mathrm{d}$ and $49.45 \times 10^{4} \mathrm{~m}^{3} / \mathrm{d}$, respectively. Under the schemes, the aquifer has not been dewatered, which meet the demand of emergency water supply.

Compared with scheme I and scheme II, scheme III is most suitable for the requirements of well layout, which has the minimum drawdown of groundwater level, and the maximum exploitation. According to the standard for domestic water consumption of urban residents (GB/T50331-2002), the domestic water consumption of urban residents is $120 \sim 180$ liters per person per day in Nanchang City. Considering the conditions of emergency water supply, the lower limit value of 120 liters per person per day is taken for calculation. For scheme III, under the conditions that the dewatered aquifers are no more than $1 / 2$ and $2 / 3$ of the original aquifer, the emergency exploitation of $36.55 \times 10^{4} \mathrm{~m}^{3} / \mathrm{d}$ and $49.45 \times 10^{4} \mathrm{~m}^{3} / \mathrm{d}$ can be provided, which could meet the emergency water demands of $54.9 \%$ and $74.3 \%$ of the local residents, respectively.

Table 1. Comparison of different exploitation schemes

\begin{tabular}{|c|c|c|c|c|c|}
\hline Schemes & $\begin{array}{c}\text { Well } \\
\text { Space } \\
(\mathrm{m})\end{array}$ & $\begin{array}{l}\text { Number } \\
\text { of wells }\end{array}$ & $\begin{array}{l}\text { Maximum } \\
\text { drawdown } \\
\quad(\mathrm{m})\end{array}$ & $\begin{array}{c}\text { Percentage } \\
\quad(\%)\end{array}$ & $\begin{array}{l}\text { Exploitation } \\
\left(10^{4} \mathrm{~m}^{3} / \mathrm{d}\right)\end{array}$ \\
\hline \multirow{2}{*}{ I } & \multirow{2}{*}{300} & \multirow{2}{*}{79} & 12.57 & 47.95 & 33.18 \\
\hline & & & 18.15 & 65.88 & 45.82 \\
\hline \multirow{2}{*}{ II } & \multirow{2}{*}{450} & \multirow{2}{*}{52} & 13.47 & 50.34 & 35.36 \\
\hline & & & 17.36 & 64.82 & 45.76 \\
\hline \multirow{2}{*}{ III } & \multirow{2}{*}{500} & \multirow{2}{*}{43} & 12.16 & 47.17 & 36.55 \\
\hline & & & 16.47 & 63.94 & 49.45 \\
\hline
\end{tabular}

Notes: The percentage is refer to the maximum percentage of dewatered aquifer in original aquifer.

\section{Conclusions}

(1) Based on groundwater seepage theory, a threedimensional visualized mathematical groundwater model was established, which could accurately characterize the actual hydrogeological characteristics of the study area and reproduces the dynamic changes of groundwater level in the study area.

(2) Under the condition that the dewatered aquifer is no more than $1 / 2$ of the original aquifer, the emergency water supply of the three schemes is $33.18 \times 10^{4} \mathrm{~m}^{3} / \mathrm{d}$, $35.36 \times 10^{4} \mathrm{~m}^{3} / \mathrm{d}$ and $36.55 \times 10^{4} \mathrm{~m}^{3} / \mathrm{d}$, respectively. Under the condition that the dewatered aquifer is no more than $2 / 3$ of the original aquifer, the emergency water supply of the three schemes is $45.82 \times 10^{4} \mathrm{~m}^{3} / \mathrm{d} 、 45.76 \times 10^{4} \mathrm{~m}^{3} / \mathrm{d}$ and $49.45 \times 10^{4} \mathrm{~m}^{3} / \mathrm{d}$, respectively.

(3) Compared with scheme I and scheme II, scheme III is the best. For scheme III, under the conditions that the dewatered aquifers are no more than $1 / 2$ and $2 / 3$ of the original aquifer, the emergency exploitation of
$36.55 \times 10^{4} \mathrm{~m}^{3} / \mathrm{d}$ and $49.45 \times 10^{4} \mathrm{~m}^{3} / \mathrm{d}$ can be provided, which could meet the emergency water demands of $54.9 \%$ and $74.3 \%$ of the local residents, respectively.

\section{Acknowledgment}

Thanks for the data support of Jiangxi Institute of Geo-Environment Monitoring. The research work described herein was funded by multi-factor urban geological survey project of Nanchang, Nanjing center, China geological survey (No: DD20189240).

\section{References}

1. Nanchang Municipal People's Government, Text of Overall Urban Planning of Nanchang City (2001 2020) (Nanchang Municipal People's Government, Nanjing, 2006)

2. C.L, Dai, B.M, Chi, Z.P, Liu, Research on city's emergency water source field in North China, Hydrogeology \& Engineering Geology, 35(4):42 46, (2008)

3. Y.Q, Zou, W.B, Zhou, Y.Y, Lan, M. Yang, Research on numerical simulation on sources of emergency water supply in Nanchang City, Hydrogeology \& Engineering Geology, 40(4):20 24, (2013)

4. H.T, Liu, Z.R, Guo, H, Dong, Analysis of the permissible utilization volume of groundwater in northwestern area and exploitation potential, Hydrology, 20(6):17 - 20, (2000)

5. X.Y, Liu, Z.X, Ma, Y.G, Yang, The ground water characteristics and its emergency water source in Nanchang, Resources Survey \& Environment, 27(1):33-38, (2006)

6. Jaroslav Vrba, Balthazar Verhagen, Groundwater for emergency situations - a methodological guide (the United Nations Educational, Scientific and Cultural organization(UNESCO), Paris, 2011).

7. C.L, Xiao, X.J, Liang, Hydrogeology (Tsinghua University Press, Beijing, 2010)

8. H.Bu, Y.S, Wang, Study on Evalutation Method to emergency water supplying sources, Shandong land and resources, 23 (8): 1-4,(2009)

9. Z.J. Luo, Y. Wang, Yan, 3-D variable parameter numerical model for evaluation of the planned exploitable groundwater resource in regional unconsolidated sediments, Journal of Hydrodynamics, 24(6):959-968,(2012)

10. Z.J. Luo, Y. Wang, S. Zhou, X. Wu, Simulation and prediction of conditions for effective development of shallow geothermal energy, Applied Thermal Engineering, 91, 370-376,(2015) 